\title{
Epidemiology, Outcomes and Risk Factors for Mortality in Critically-III Women Admitted to an Obstetric High Dependency Unit in a Resource- Limited Setting
}

Claudia Marotta

Doctors with Africa CUAMM

Luigi Pisani

Mahidol University , Bangkok

Francesco Di Gennaro ( $\sim$ cicciodigennaro@yahoo.it )

Istituto Neurologico Mediterraneo https://orcid.org/0000-0003-3453-5647

Francesco Cavallin

Indipendent statistician

\section{Sarjoh Bah}

Princess Christian Maternity Hospital,Freetown Sierra Leone

\section{Vincenzo Pisani}

Doctors with Africa Cuamm, Sierra Leone

\section{Rashan Haniffa}

Mahidol Oxford Tropical Medicine Research Unit

\section{Abi Beane}

Mahidol Oxford Tropical Medicine Research Unit

\section{Daniele Trevisanuto}

Department of Woman's and child's Health, University of Padua, Italy

\section{Eva Hanciles}

University of Sierra leone

Marcus J Schultz

Mahidol Oxford Tropical Medicine Research Unit

\section{Michael Koroma}

Princess Christian Maternity Hospital, Freetown, Sierra Leone

\section{Giovanni Putoto}

Doctors with Africa Cuamm, Section of Operational Research, Italy

\section{Research}


Keywords: High dependency unit, critical care, obstetric critical care, Sierra Leone, outcome, maternal mortality

Posted Date: May 28th, 2020

DOI: https://doi.org/10.21203/rs.3.rs-30664/v1

License: (c) (i) This work is licensed under a Creative Commons Attribution 4.0 International License. Read Full License 


\section{Abstract}

Background: A better understanding of the context specific epidemiology, outcomes and risk factors for death of critically ill parturients in resource-poor hospitals is needed in order to tackle the still alarming inhospital maternal mortality in African countries.

Methods: One-year retrospective cohort in a referral maternity hospital in Freetown, Sierra Leone. Primary data source was the patient chart. The primary endpoint was the association between risk factors and HDU mortality. The study was registered on ClinicalTrials.gov (study identifier NCT04121234).

Results: 523 patients (median age 25 years, IQR 21-30) were admitted to the HDU for a median of 2 (IQR 1-3) days. $65 \%$ were referred with a red obstetric early warning score (OEWS) code, representing 1.17 cases per HDU bed per week. 11\% of patients died in HDU, mostly in the first 24 hours from admission. The factors independently associated with HDU mortality were: ward rather than post-operative referrals (odds ratio $(\mathrm{OR}), 3.21$ [95\%-confidence interval $(\mathrm{Cl}) 1.48$ to 7.01]; $\mathrm{P}=0.003$ ), admissions with a red vs. yellow/green OEWS (OR, 3.66 [95\%-Cl 1.15 to 16.96]; $\mathrm{P}=0.04$ ), responsiveness to pain or unresponsiveness on the AVPU scale (OR, 5.25 [95\%-Cl 2.64 to 10.94]; $P=<0.0001)$, use of vasopressors (OR, 3.24 [95\%-Cl 1.32 to 7.66]; $\mathrm{P}=0.008)$. Higher SpO 2 was associated with improved survival $(\mathrm{OR}, 0.95$ [95\%-Cl 0.91 to 0.98$] ; \mathrm{P}=0.007$ ).

Conclusions: Critically ill parturients were predominantly referred with a red OEWS code and usually required intermediate care for 48 hours. Mortality is high and mostly occurs during first day. Medical admission, a red OEWS code, a poor neurological and hemodynamic status were independently associated with mortality, while adequate oxygenation was associated with survival.

Trial Registration: The study was registered on ClinicalTrials.gov (study identifier NCT04121234).

\section{Plain English summary}

Sierra Leone is one of the countries with the highest maternal mortality rate of the world. Understanding of critical care issues and potential interventions is lagging behind approaches in the primary care and obstetric domain.

This study, reporting data from 525 patients admitted to an obstetric HDU, to date represents the largest cohort of critically-ill parturients from a low-income country.

At multivariable analysis, being referred from the ward rather than being post-operative (OR $3.21,95 \% \mathrm{Cl}$ 1.48 to 7.01 ), red OEWS code (OR 3.66, 95\% $\mathrm{Cl} 1.15$ to 16.96), being responsive to pain or unresponsive on AVPU scale (OR 5.25, 95\% $\mathrm{Cl} 2.64$ to 16.96) at admission, use of vasopressors at admission (OR 3.24, $95 \% \mathrm{Cl} 1.32$ to 7.66$)$ were independent risk factors for mortality, while higher $\mathrm{SpO}_{2}(\mathrm{OR} 0.95,95 \% \mathrm{Cl} 0.91$ to 0.99 ) was associated with increased survival. 
The findings of this study can be summarized as follows (1) in a low-resource referral maternity hospital one out of 14 deliveries needed critical care attention, with a crude mortality rate of $10.5 \%$; (2) independent predictors of mortality were poor neurological status, a red OEWS code at admission to HDU and the use of vasopressors during the stay; (3) higher oxygenation was associated with survival. Clinicians and policy makers may use these findings to prioritize simple critical care interventions to address maternal mortality in a high burden scenario.

\section{Background}

Maternal mortality is globally declining but still represents a heavy burden in some regions of the world (1). Above all countries, Sierra Leone has the primacy with the highest maternal mortality ratio (MMR) of 1.360 deaths per 100.000 live births in 2015 (1). During the last decades, in order to reach the Millennium Development Goal (MDG) number 5, (2) global strategies have prioritized family planning, access to care and birth with a skilled attendant (3). Intensive care interventions have lagged behind in the effort to reduce maternal mortality and morbidity. The transition from the MDGs to the Sustainable Development Goals (SDGs) in 2015 led to increased attention to the continuum of care for women, thus including critical care (4).

Resource-limited settings face the highest burden of obstetric critical care, including conditions such as eclampsia, haemorrhage, coagulopathy and sepsis (5). All these conditions may benefit from an increased short-term level of monitoring and care, as provided by high dependency units (HDUs) (6). HDUs are distinct organizational environments for clinical activity and care, operating in strict cooperation with other departments in the hospital (7). Commonly recognized aims for HDUs are the monitoring and support of threatened or failing vital functions in critically ill patients. In particular, focused interventions as multiparametric monitoring, accurate intravenous fluid management, rational oxygen administration, pain management, blood transfusions and renal output monitoring in the early postoperative period, may impact outcomes for critical pregnant women in a referral Comprehensive Emergency Obstetric Care Service (CEmOC) (8).

The characteristics and needs of obstetric critically-ill patients, and the potential role of patient centralization and obstetric HDUs in resource-limited settings, remain scarcely explored. The current study aimed to investigate the epidemiology, clinical outcomes and risk factors for mortality of critically ill-parturients admitted in an obstetric HDU in a setting with severe limitations in resources and an extreme maternal mortality.

\section{Methods}

\section{Study design}

This is a retrospective study in women admitted to the HDU of Princess Christian Maternity Hospital (PCMH), Freetown, Sierra Leone, from $2^{\text {nd }}$ October 2017 to $2^{\text {nd }}$ October 2018 . The study protocol was 
approved by the Sierra Leone Ethics and Scientific Review Committee on the $18^{\text {th }}$ December 2018. The need for informed consent was waived. The study was registered on ClinicalTrials.gov (study identifier NCT04121234).

\section{Study setting}

With 129 beds, the PCMH is the largest maternity referral hospital in Sierra Leone with a reference population of 1.5 million inhabitants. $\mathrm{PCMH}$ is a primarily obstetric institution with approximately 9,000 admissions and 6,500 deliveries per year $(9,10)$. One-third of the parturients develop major obstetric emergencies, including peripartum haemorrhage, sepsis and pre-eclampsia $(9,10)$. Operating theatre facilities are essential, anaesthetic service is available with a majority of spinal anaesthesia procedures.

The HDU is a 4-bed medium care unit, with a basic model of intermediate intensive care defined on few essential criteria such as a high nurse/patient ratio, close monitoring of vital signs, personalized intravenous fluid and vasopressor therapy management, a rational use of oxygen and a very basic point of care laboratory (11). Electricity and clean water are continuously available, while oxygen is generated through bedside oxygen concentrators with a maximal output of $10 \mathrm{l} / \mathrm{min}$ and maximal purity of $96 \%$. No mechanical ventilators or dialysis apparatus are available in the unit or hospital. A basic neonatal ICU is available as a separate entity.

\section{Patients}

Patients were eligible if (1) admitted to the HDU, (2) being pregnant or within 42 days after termination of pregnancy (12), (3) between $2^{\text {nd }}$ October 2017 and $2^{\text {nd }}$ October 2018. No exclusion criteria were used.

\section{Study endpoints}

The primary endpoint was the association between several potentially modifiable and non-modifiable factors, as standardly collected in the patient chart of each patient, and mortality during HDU stay. Secondary endpoints were demographic characteristics, reasons of admission, obstetric early warning score (OEWS) at admission, treatments received, vital parameters on presentation, admission time (night/day or weekend/working days), length of stay in HDU, discharge destination and hospital mortality.

\section{Data collection}

A set of predefined variables was assessed at hospital admission, HDU admission and at discharge from HDU. The primary data source was the HDU patient chart, with data crosschecked with the hospital patient charts and the HDU admission book for quality control purpose. Data on hospital deliveries, admissions and mortality were extracted from the hospital register and the maternal mortality hospital 
database. Data were retrospectively collected by a study physician (CM) and included: patient demographics; admission date and source; main reason for admission in hospital (classified as by the WHO handbook on Monitoring emergency obstetric care (12) as: complication of abortion; ante-partum haemorrhage (APH), ectopic pregnancy, obstructed labour, postpartum haemorrhage (PPH), preEclampsia(PE)/eclampsia, puerperal Sepsis, uterine rupture (UR), others); main reason for admission to the HDU were classified at the source as: haemodynamic instability, sepsis, haemorrhage, acute renal failure, neurological impairment, respiratory distress, severe malaria, coagulopathy or other diagnoses. These were standardized diagnoses based on the clinical assessment of the attending physician and thus not based on strict research case definitions.

Vital signs and treatments collected at admission included body temperature, heart rate, respiratory rate, neurological status according to the AVPU scale, systolic and diastolic blood pressure, transcutaneous peripheral saturation $\left(\mathrm{SpO}_{2}\right)$. The ratio between $\mathrm{SpO}_{2}$ and fraction of inspired oxygen $\left(\mathrm{SpO}_{2} / \mathrm{FiO}_{2}\right)$ was computed to better assess oxygenation in patients receiving oxygen. A modified obstetric modified early warning score (OEWS) was also computed from vital parameters (13).

Specific treatments received at any point during HDU stay were extracted from the patient file and included: oxygen supplementation, use of vasopressors, whole blood transfusions, antibiotic therapy, use of magnesium sulphate for eclamptic seizures prevention and use of hydralazine for antihypertensive purposes. Point of care laboratory parameters such as capillary lactates levels and haemoglobin $(\mathrm{Hb})$ levels were collected when available. Date and time of hospital admission was collected whenever available. Length of stay in HDU (LOS) and patient outcomes (classified as death in HDU, discharge to ward, or transfer to other facility) were reported at discharge.

\section{Definitions}

The modified obstetric early warning score (OEWS) uses core physiological parameters such as systolic (SBP) and diastolic blood pressure (DBP), heart rate (HR), respiratory rate (RR) and temperature to identify deteriorating obstetric patients demanding extra attention (13). The OEWS used in this study, and in the hospital at the time of the data collection, ranges from 0 to 10 points, with a green colour code granted with a total OEWS of 1-2, a yellow colour code for total OEWS of 3 to 5 , and a red colour code attributed to any patient with a OEWS above 5, or any danger sign (any among a SBP $>160 \mathrm{~mm} \mathrm{Hg}$ or $<80 \mathrm{~mm} \mathrm{Hg}$, a DBP of $>110 \mathrm{~mm} \mathrm{Hg}$, a HR $<60$ or $>120, \mathrm{RR}>31$ or $<10$ and a body temperature $>38.5^{\circ} \mathrm{C}$ or $<35^{\circ} \mathrm{C}$ ).

Patients were stratified according to severity on HDU admission in two groups i.e. with patients having a red OEWS in one group and patients having a green or yellow OEWS in the less severe group.

The AVPU is a simplification of the Glasgow Coma Scale useful to rapidly grade a patient's gross level of mental status based on four criteria (Alert, Verbally responsive, responsive to Painful stimulus, Unresponsive). The ratio between $\mathrm{SpO}_{2}$ and fraction of inspired oxygen $\left(\mathrm{FiO}_{2}\right)$ was computed by deriving the $\mathrm{FiO}_{2}$ from the oxygen therapy in litres by the following formula $\mathrm{FiO}_{2}=0.21+02(1 / \mathrm{min}) \times 0.03(14)$. 
Death during HDU stay was defined as death occurred from referral to HDU to discharge from HDU. Hospital mortality was defined as death occurring during the whole hospital stay. Time from admission to hospital to referral to HDU was computed from the relevant variables whenever these where available.

\section{Statistical analysis}

No formal sample size was calculated a priori, and the study included all women admitted during the first year of activity of the HDU. Continuous data were expressed as median and interquartile range (IQR), and categorical data as number and percentage. Mortality rate, AVPU classification and OEWS score were compared among reasons for referral to HDU using Chi Square test. The proportion of patients admitted with a red code per HDU bed per week was calculated by dividing the number of patients with red code per HDU bed over the study period. Patients with a red code at the admission were compared with the ones presenting with a yellow or green code.

The association between mortality and each clinically relevant variable was explored using logistic regression models (unadjusted analysis). Independent risk factors for mortality were investigated using a logistic regression model including a set of candidate predictors at admission (adjusted analysis). The limited number of deaths restricted the number of candidate predictors that could be included in the first stage of model selection. Owing to collinearity with OEWS, some variables (temperature, heart rate, respiratory rate, $\mathrm{SpO}_{2} / \mathrm{FiO}_{2}$ ratio, systolic and diastolic blood pressures) were not included in the model (15). Other variables (age, $\mathrm{Hb}$, admission during night and weekend admission) were not included in the model according to unadjusted analysis of mortality. The final model included source of admission, OEWS, $\mathrm{SpO}_{2}$, AVPU, use of oxygen and use of vasopressors at admission. Model selection was performed by Akaike's information criterion reduction. Effect sizes were presented as odds ratios (OR) with 95\% confidence intervals $(\mathrm{Cl})$.

All analyses were 2-sided and a p-value less than 0.05 was considered statistically significant. Statistical analysis was performed using R 3.5 (R Foundation for Statistical Computing, Vienna, Austria) (16).

\section{Results}

\section{Patients}

In the year the study ran, 523 patients (median age 25 years, IQR 21-30) were admitted to the HDU. The incidence of HDU admissions was 72 per 1000 deliveries, which equates to $7.2 \%$ or $1 \mathrm{HDU}$ admission per 14 deliveries. Before referral to HDU, admission to the hospital was due to pre-eclampsia or eclampsia (117 women, 22.4\%), antepartum haemorrhage (APH), including abruptio placentae or placenta praevia (85 women, 16.3\%), uterine rupture (55 women, 10.5\%), postpartum haemorrhage (PPH) (66 women, 12.6\%), ectopic pregnancy (53 women, 10.1\%), puerperal sepsis (49 women, 9.4\%), obstructed labour (28 women, $5.4 \%$ ), complications of abortion (12 women, $2.3 \%$ ) or other diagnoses (58 women, $11.1 \%$ ). 
Patient characteristics at admission to HDU stratified by severity level are reported in Table 1. 381 patients (72.8\%) received surgery (mainly caesarean section or laparotomy). Median time of arrival to HDU was 9 hours (IQR 3-38 h), bit it should be noted that this variable was often not reported (only in 39\% of records). The most frequent reasons for referral to HDU were hemodynamic instability (56.7\%) and sepsis (12.4\%). Half of patients were alert at referral (51.3\%) but the majority had a red OEWS (65.1\%). 


\begin{tabular}{|c|c|c|c|c|}
\hline Characteristic & $\begin{array}{l}\text { All patients } \\
(\mathrm{n}=523)\end{array}$ & $\begin{array}{l}\text { Red OEWS } \\
(n=330)\end{array}$ & $\begin{array}{l}\text { Green or yellow OEWS } \\
(n=177)\end{array}$ & p-value \\
\hline \multicolumn{5}{|l|}{$\begin{array}{l}\text { ADMISSION } \\
\text { CHARACTERISTICS }\end{array}$} \\
\hline Age, years ${ }^{a b}$ & $25(21-30)$ & $25(20-30)$ & $26(22-32)$ & 0.08 \\
\hline Reason for referral to HDU: & & & & 0.38 \\
\hline Hemodynamic instability & $297(56.8)$ & $181(54.9)$ & $107(60.4)$ & \\
\hline Sepsis & $65(12.4)$ & 45 (13.6) & $18(10.2)$ & \\
\hline Acute kidney failure & $19(3.6)$ & $9(2.7)$ & $9(5.1)$ & \\
\hline Neurological impairment & $41(7.8)$ & $27(8.2)$ & $13(7.3)$ & \\
\hline Respiratory distress & $51(9.8)$ & $38(11.5)$ & $12(6.8)$ & \\
\hline Severe malaria & $9(1.7)$ & $6(1.8)$ & $3(1.7)$ & \\
\hline Coagulopathy & $23(4.4)$ & $15(4.6)$ & $7(4.0)$ & \\
\hline Other diagnoses & $18(3.4)$ & $9(2.7)$ & $8(4.5)$ & \\
\hline Source: & & & & 0.81 \\
\hline Operation room & $346(66.2)$ & $216(65.5)$ & $119(67.2)$ & \\
\hline Outpatient department & $53(10.1)$ & $33(10.0)$ & $19(10.8)$ & \\
\hline Ward & $124(23.7)$ & $81(24.5)$ & $39(22.0)$ & \\
\hline \multicolumn{5}{|l|}{ Admission time: } \\
\hline During night shift & $156(29.8)$ & $97(29.4)$ & $53(29.9)$ & 0.98 \\
\hline During weekend & $129(24.7)$ & $79(23.9)$ & $47(26.6)$ & 0.59 \\
\hline \multicolumn{5}{|l|}{ CLINICAL PARAMETERS } \\
\hline $\begin{array}{l}\text { Obstetric early warning } \\
\text { score: }^{c}\end{array}$ & $110(21.6)$ & 0 & $110(62.1)$ & - \\
\hline Green & $67(13.2)$ & 0 & 67 (37.9) & \\
\hline Yellow & $330(65.1)$ & $330(100.0)$ & 0 & \\
\hline Red & & & & \\
\hline Temperature, ${ }^{\circ} \mathrm{C}$ ae & $\begin{array}{l}36.5(36.0- \\
36.9)\end{array}$ & $\begin{array}{l}36.5(36.0- \\
36.9)\end{array}$ & $36.4(36.0-36.8)$ & 0.30 \\
\hline $\begin{array}{l}\text { Heart rate, beats per minute } \\
\text { ae }\end{array}$ & $113(99-129)$ & $125(110-136)$ & $100(90-108)$ & $<0.0001$ \\
\hline Respiratory rate, breaths per & $28(24-34)$ & $32(26-39)$ & $24(22-28)$ & $<0.0001$ \\
\hline
\end{tabular}




\begin{tabular}{|c|c|c|c|c|}
\hline $\mathrm{SpO}_{2}, \%$ ad & 98 (97-99) & 98 (97-99) & 98 (97-99) & 0.008 \\
\hline $\mathrm{SpO}_{2} / \mathrm{FiO}_{2}$ ratio af & $467(462-471)$ & $467(452-471)$ & $467(462-471)$ & 0.001 \\
\hline AVPU scale: $\mathrm{g}$ & & & & 0.07 \\
\hline \multirow{4}{*}{$\begin{array}{l}\text { Alert } \\
\text { Voice } \\
\text { Pain } \\
\text { Unresponsive }\end{array}$} & $259(51.3)$ & $160(48.9)$ & $99(55.9)$ & \\
\hline & $73(14.4)$ & $42(12.9)$ & $30(16.9)$ & \\
\hline & $69(13.7)$ & $48(14.7)$ & $21(11.9)$ & \\
\hline & $104(20.6)$ & $77(23.5)$ & $27(15.3)$ & \\
\hline $\begin{array}{l}\text { Systolic blood pressure, } \\
\mathrm{mmHg} \text { ag }\end{array}$ & $124(110-142)$ & $128(110-151)$ & $122(110-136)$ & 0.01 \\
\hline $\begin{array}{l}\text { Diastolic blood pressure, } \\
\mathrm{mmHg}^{\text {ag }}\end{array}$ & $78(60-90)$ & 79 (60-99) & $76(62-85)$ & 0.15 \\
\hline \multicolumn{5}{|l|}{ BIOLOGY } \\
\hline $\begin{array}{l}\text { Capillary lactates levels, } \\
\mathrm{mmol} / \mathrm{L} \text { ah }\end{array}$ & $6.0(3.5-10.1)$ & $6.5(3.5-11.3)$ & $5.2(2.6-7.7)$ & - \\
\hline Hemoglobin, $\mathrm{g} / \mathrm{dl}$ ai & $8.3(6.4-10.5)$ & $8.1(6.1-10.6)$ & $8.5(7.0-10.49$ & 0.42 \\
\hline
\end{tabular}

Table 1

Patient characteristics at admission to HDU of PCMH.

Patient characteristics at admission were not significantly different between patients with red vs. green/yellow OEWS, except for heart rate, respiratory rate, systolic blood pressure (included in the computation of OEWS), $\mathrm{SpO} 2$ and $\mathrm{SpO}_{2} / \mathrm{FiO}_{2}$ ratio. The number of patients with red code per $\mathrm{HDU}$ bed over the study period was 82.5 , representing 1.17 cases per HDU bed per week. During hospital stay, oxygen therapy was administered to 116 patients $(22.2 \%)$, vasopressors to $68(13.0 \%)$, transfusions to $263(50.3 \%)$, antibiotics to 109 (20.8\%), magnesium to $72(13.8 \%)$ and hydralazine to $74(14.1 \%)$.

\section{Outcome}

Fifty-five patients died in HDU (10.5\%), of whom 72.7\% died within 24 hours from HDU admission. Thirtytwo (58.2\%) patients died during night shift while 15 (27.3\%) patients died during weekend days. Hospital mortality was $10.7 \%$, as one patient deceased in the ward after HDU discharge. Specific HDU mortality 
rate was different among reasons for referral to HDU ( $p<0.0001)$, being lowest in patients with hemodynamic instability (4\%) and highest in those with coagulopathy (35\%) (Figure 1).

Four out of five patients $(n=428,81.9 \%)$ improved and were transferred to the ward after a median stay of 2 days (IQR 1-3). A total of $6.3 \%$ patients were transferred to an external ICU or to other hospitals after a median stay of 2 days (IQR 1-4) while only 7 patients (1.3\%) were discharged directly at home after a median stay of 5 days (IQR 4-6).

\section{Factors associated with HDU mortality}

At unadjusted analysis (Table 2), mortality was associated with referral from out-patient department (OPD) or ward $(p=0.0005)$, and with admission in yellow or red OEWS code $(p=0.0008)$. Mortality was also associated with low $\mathrm{SpO}_{2}(p<0.0001)$, high respiratory rate $(p=0.03)$, hypertensive disorders $(p=0.0001)$, and being responsive to pain or unresponsive on the AVPU scale $(p<0.0001)$. Mortality was higher in patients receiving oxygen $(p<0.0001)$ or vasopressors $(p<0.0001)$ at admission. 


\begin{tabular}{|c|c|c|c|c|}
\hline Variables & $\begin{array}{l}\text { Dead } \\
(n=55)\end{array}$ & $\begin{array}{l}\text { Alive } \\
(n=468)\end{array}$ & $\begin{array}{l}\text { Odds ratio ( } 95 \% \\
\text { confidence interval) }\end{array}$ & P-value \\
\hline Age, year ab & $25(21-34)$ & $25(21-30)$ & 1.02 (0.98 to 1.07$)$ & 0.26 \\
\hline Source: & & & & 0.0005 \\
\hline Operation room & $23(6.6)$ & $323(93.4)$ & Reference & \\
\hline Outpatient department & $10(18.9)$ & $43(81.1)$ & 3.26 (1.40 to 7.17$)$ & \\
\hline Ward & $22(17.7)$ & $102(82.3)$ & 3.03 (1.61 to 5.68$)$ & \\
\hline Admission during night: & & & & 0.90 \\
\hline No & $39(10.6)$ & $328(89.4)$ & Reference & \\
\hline Yes & $16(10.3)$ & $140(89.7)$ & $0.96(0.51$ to 1.75$)$ & \\
\hline Weekend admission: & & & & 0.64 \\
\hline No & $40(10.2)$ & $345(89.8)$ & Reference & \\
\hline Yes & 15 (11.6) & $114(88.4)$ & $1.16(0.60$ to 2.14$)$ & \\
\hline OEWS: ${ }^{c}$ & & & & 0.0008 \\
\hline Green & $3(2.7)$ & $107(97.3)$ & Reference & \\
\hline Yellow & $5(7.5)$ & $62(92.5)$ & 2.88 (0.68 to 14.41$)$ & \\
\hline Red & $46(13.9)$ & $284(86.1)$ & 5.78 (2.06 to 24.14$)$ & \\
\hline $\mathrm{SpO} 2, \%$ ad & $96(90-98)$ & $98(97-99)$ & 0.91 (0.88 to 0.94$)$ & $<0.0001$ \\
\hline Temperature, ${ }^{\circ} \mathrm{C}$ ae & $\begin{array}{l}36.4(35.7- \\
37.1)\end{array}$ & $\begin{array}{l}36.5(36.1- \\
36.8)\end{array}$ & 1.24 (0.88 to 1.76$)$ & 0.23 \\
\hline Heart rate, beats per minute ae & $\begin{array}{l}120(98- \\
1409\end{array}$ & $\begin{array}{l}112(99- \\
128)\end{array}$ & 1.01 (0.99 to 1.02$)$ & 0.38 \\
\hline $\begin{array}{l}\text { Respiratory rate, movements } \\
\text { per minute af }\end{array}$ & $32(27-45)$ & $28(24-34)$ & $1.02(1.00$ to 1.04$)$ & 0.03 \\
\hline $\mathrm{SpO}_{2} / \mathrm{FiO}_{2}$ ratio af & $\begin{array}{l}438(237- \\
462)\end{array}$ & $\begin{array}{l}467(462- \\
471)\end{array}$ & 0.99 (0.99 to 0.99$)$ & $<0.0001$ \\
\hline AVPU: 9 & & & & $<0.0001$ \\
\hline \multirow{2}{*}{$\begin{array}{l}\text { Alert/Vocal } \\
\text { Pain/Unresponsive }\end{array}$} & $17(5.1)$ & $315(94.9)$ & Reference & \\
\hline & $35(20.2)$ & $138(79.8)$ & 4.70 (2.58 to 8.86$)$ & \\
\hline $\begin{array}{l}\text { Systolic blood pressure, } \\
\mathrm{mmHg} \text { ag }\end{array}$ & $\begin{array}{l}113(92- \\
139)\end{array}$ & $\begin{array}{l}125(112- \\
143)\end{array}$ & 0.98 (0.97 to 0.99$)$ & 0.0001 \\
\hline
\end{tabular}




\begin{tabular}{|c|c|c|c|c|}
\hline $\begin{array}{l}\text { Diastolic blood pressure, } \\
\mathrm{mmHg} \text { ag }\end{array}$ & $65(40-80)$ & $79(60-91)$ & 0.97 (0.96 to 0.98$)$ & 0.0001 \\
\hline Hemoglobin, $g / d l$ ah & $\begin{array}{l}8.0(6.0- \\
10.4)\end{array}$ & $\begin{array}{l}8.3(6.5- \\
10.5)\end{array}$ & 0.95 (0.85 to 1.06$)$ & 0.36 \\
\hline Oxygen at admission: & & & & $<0.0001$ \\
\hline No & $36(8.0)$ & $416(92.0)$ & Reference & \\
\hline Yes & $19(26.8)$ & $52(73.2)$ & 4.22 (2.23 to 7.84$)$ & \\
\hline Vasopressors at admission: & & & & $<0.0001$ \\
\hline No & $42(8.6)$ & $446(91.4)$ & Reference & \\
\hline Yes & $13(37.1)$ & $22(62.9)$ & 6.27 (2.89 to 13.23$)$ & \\
\hline
\end{tabular}

\section{Table 2}

Unadjusted analysis of mortality.

At multivariable analysis (Table 3), being referred from the ward rather than being post-operative (OR $3.21,95 \% \mathrm{Cl} 1.48$ to 7.01 ), red OEWS code (OR $3.66,95 \% \mathrm{Cl} 1.15$ to 16.96 ), being responsive to pain or unresponsive on AVPU scale (OR 5.25, 95\% Cl 2.64 to 16.96) at admission, use of vasopressors at admission (OR $3.24,95 \% \mathrm{Cl} 1.32$ to 7.66 ) were independent risk factors for mortality, while higher $\mathrm{SpO}_{2}$ (OR $0.95,95 \% \mathrm{Cl} 0.91$ to 0.99 ) was associated with increased survival. 


\begin{tabular}{|c|c|c|}
\hline Variables & Odds ratio ( $95 \%$ confidence interval) & P-value \\
\hline \multicolumn{3}{|l|}{ Source: } \\
\hline Operation room & Reference & - \\
\hline Outpatient department & 2.18 (0.76 to 5.77$)$ & 0.13 \\
\hline Ward & 3.21 (1.48 to 7.01$)$ & 0.003 \\
\hline \multicolumn{3}{|l|}{ OEWS: } \\
\hline Green & Reference & - \\
\hline Yellow & 3.14 (0.68 to 17.57$)$ & 0.15 \\
\hline Red & 3.66 (1.15 to 16.96$)$ & 0.04 \\
\hline Sp02, \% & 0.95 (0.91 to 0.98$)$ & 0.007 \\
\hline AVPU: & & $<0.0001$ \\
\hline \multirow{2}{*}{$\begin{array}{l}\text { Alert/Vocal } \\
\text { Pain/Unresponsive }\end{array}$} & Reference & \\
\hline & 5.25 (2.64 to 10.94$)$ & \\
\hline Oxygen at admission: & & 0.14 \\
\hline No & Reference & \\
\hline Yes & 1.82 (0.81 to 3.93$)$ & \\
\hline Vasopressors at admission: & & 0.008 \\
\hline No & Reference & \\
\hline Yes & 3.24 (1.32 to 7.66$)$ & \\
\hline \multicolumn{3}{|c|}{$\begin{array}{l}\text { Owing to collinearity with OEWS, some variables (temperature, heart rate, respiratory rate, SpO2/FiO) } \\
\text { ratio, systolic and diastolic blood pressures) were not included in the model. Other variables (age, } \\
\text { hemoglobin, admission during night and weekend admission) were not included in the model } \\
\text { according to unadjusted analysis of mortality. Finally, model selection was performed by AIC } \\
\text { reduction. } \\
\text { OEWS, modified obstetric early warning score; AVPU, alert, voice, pain unresponsive scale; SpO2, } \\
\text { transcutaneous saturation of hemoglobin; FiO2, fraction of inspired oxygen }\end{array}$} \\
\hline
\end{tabular}

Table 3

Multivariable analysis of mortality.

\section{Discussion}

The findings of this study can be summarized as follows (1) in a low-resource referral maternity hospital one out of 14 deliveries needed critical care attention, with a crude mortality rate of $10.5 \%$; (2) independent predictors of mortality were poor neurological status, a red OEWS code at admission to HDU and the use of vasopressors during the stay; (3) higher oxygenation was associated with survival. 
To the best of our knowledge this is the first study reporting data from an obstetric African HDU and represents to date the largest cohort of critically ill parturients from a low-income country. Other strengths of this study were the attempt to build a consecutive patient cohort, the moderately long time frame of observation and the referral status of the hospital, allowing a comprehensive picture of this vulnerable patient group.

The rate of HDU admission was much higher than previous reports involving intensive care units (ICUs) rather than HDUs (17-19), This is consistent with both the higher burden of obstetric critical care in Sierra Leone (1) and the intermediate level of care of the HDU compared to ICU. In particular, this study was conducted in the HDU of an urban high volume maternity hospital and the only one qualified for CEmOC in an entire region. Low resources countries have a disproportionally greater share of obstetric critical illness, and yet critical care facilities remain scarce. This is shown in several ICU cohort studies from Nigeria $(17,20,21)$. In fact, while in high-resources countries around $0.9-1 \%$ of pregnant women require ICU admission, this figures may rise up to $10 \%$ in low resources countries (22). Also, non-standardized admission criteria for both HDU and ICU should be considered as a determinant of variability in obstetrics comparative epidemiology (23). Although a consensus on obstetric critical care admission criteria would be helpful, this is difficult to define since these are heavily influenced by the conditions of the single institution and country (24).

Specific causes of HDU admission are comparable to other cohorts $(17,19,20,25)$, with haemorrhage (both APH and PPH), severe pre-eclampsia and sepsis representing the most significant burden. Of note, uterine rupture as a reason for critical care referral significantly affected this cohort in Sierra Leone, with one in ten patients admitted with this potentially fatal condition. This finding confirms how this extreme complication still affects African women even in urban centres with wide access to primary care, as was also highlighted in a previous study on Caesarean Section infections in the same hospital(26).

Critically ill parturients managed in the HDU were extremely young, even younger than reported from other countries $(25,27)$, and necessitated for critical attention for approximately two days. This relatively short time is in line with other ICU-based investigations $(19,27,28)$ and promotes the cost effectiveness of intermediate critical care interventions especially seen the high burden of red OEWS codes on admission.

One in ten admitted patients died in HDU, mainly within the first 24 hours from admission and during nightshift. This figure is higher than what reported in cohort studies from high resources countries, where less than $5 \%$ of obstetric patients admitted to the ICU had a poor outcome (19). However it is a crude mortality rate comparable to previous investigations in India and Nigeria $(6,21)$ that spotlight the still alarming hospital mortality of critically ill women.

Main predictors for HDU mortality were in line with results from a recent systematic review of early warning systems retained a high predictive capacity for maternal death among critically ill obstetric patients (27). Despite the intra operatory derangements and risk of post operatory complications, the referral from the operating room was less likely associated with poor outcome compared to medical admissions. This relatively unexpected finding prompts to further refinements of early referral systems to 
allow early centralization of unstable medical patients that should not be left under the responsibility of overwhelmed and under resourced ward nurses. The HDU under study had no access to mechanical ventilators and thus the positive modifiable effect of higher $\mathrm{SpO}_{2}$ is attributable uniquely to careful oxygen therapy.

Our study has several limitations. First, the retrospective design limited the availability of some clinically relevant variables such as parity, details on antenatal care, socio-economic information and foetal outcomes that were not collected in HDU charts (29). Secondly, although reason for admission in HDU were similar to what reported in other cohorts (22), the generalizability of the findings is limited to similar settings with extreme maternal mortality. These are however the settings where data is most lacking and thus needed. Thirdly, as for all retrospective investigations, no quality control or standardized procedures were applicable on the vital parameters and other variables collection. Fourthly, the exact discharge ward for transfers was not detailed in the hospital charts. Finally, the number of outcome events restricted the number of candidate predictors that could be included in the first stage of model selection.

In conclusion, these findings tackle the scarcity of data on in-hospital obstetric critical illness and mortality. Clinicians and policy makers may use these findings to prioritize simple critical care interventions to address maternal mortality in a high burden scenario.

\section{Declarations}

\section{Ethics approval and consent to participate:}

The study protocol was approved by the Sierra Leone Ethics and Scientific Review Committee on the $18^{\text {th }}$ December 2018.

\section{Consent for publication:}

patient gave informed consent for publication.

\section{Availability of data and materials:}

not applicable.

\section{Competing interests:}

none

\section{Funding:}


none.

\section{Authors' contributions:}

all authors contribute to the realization of the manuscript

\section{Acknowledgements}

We thank the HDU nursing team for the committed clinical care and strong daily collaboration during this study. We also thank the Princess Christian Maternity Hospital leadership and treating teams, Hospital Management Team and archive staff.

\section{References}

1. WHO, UNICEF, UNFPA WBG, Division and the UNPD. Trends in maternal mortality 1990 to 2015. $2015 ; 1-96$.

2. Sachs JD, Mcarthur JW. The Millennium Project: a plan for meeting the Millennium. Lancet. 2015;365:347-53.

3. Organization WH. Making pregnancy safer: the critical role of the skilled attendant: a joint statement by WHO, ICM and FIGO. Geneva, Switz WHO. 2004;

4. Resources SO. Sustainable Development Goals ( SDGs ) Selected Online Resources. 2015; (September):25-7.

5. Baskett TF. Epidemiology of obstetric critical care. Best Pract Res Clin Obstet Gynaecol. 2008;22(5):763-74.

6. Zeeman GG, Wendel GD, Cunningham FG. A blueprint for obstetric critical care. Am J Obstet Gynecol. 2003;188(2):532-6.

7. Valentin A, Ferdinande P. Recommendations on basic requirements for intensive care units: Structural and organizational aspects. Intensive Care Med. 2011;37(10):1575-87.

8. Price LC, Slack A, Nelson-Piercy C. Aims of obstetric critical care management. Vol. 22, Best Practice and Research: Clinical Obstetrics and Gynaecology. 2008. p. 775-99.

9. PCMH; Doctor with Africa CUAMM. Princess Christian Maternity Hospital - Annual Report 2017. 2017.

10. PCMH; Doctor with Africa CUAMM. Princess Christian Maternity Hospital - Annual Report 2018. 2018.

11. Hospital Management Team P. Conceptual framework for the planning of a High Dependency Unit at Princess Christian Maternity Hospital (PCMH). Freetown; 2017.

12. World Health Organization, United Nations Population Fund MS of PHAMD and D\& UNCF (UNICEF). (2009). WHO. Monitoring emergency obstetric care: a handbook.o Title. 2009.

13. Paternina-Caicedo A, Miranda J, Bourjeily G, Levinson A, Dueñas C, Bello-Muñoz C, et al. Performance of the Obstetric Early Warning Score in critically ill patients for the prediction of maternal death. Am J 
Obstet Gynecol. 2017 Jan;216(1):58.e1-58.e8.

14. Riviello ED, Kiviri W, Twagirumugabe T, Mueller A, Banner-Goodspeed VM, Officer L, et al. Hospital Incidence and Outcomes of the Acute Respiratory Distress Syndrome Using the Kigali Modification of the Berlin Definition. Am J Respir Crit Care Med. 2016 Jan;193(1):52-9.

15. Harrell F. Regression Modeling Strategies. New York NS-V, editor. 2001.

16. Team, R Core R Focundation for Statistical Computing, Vienna A. R: A language and environment for statistical computing. 2018. p. R Focundation for Statistical Computing, Vienna, A.

17. Ozumba BC, Ajah LO, Obi VO, Umeh UA. Pattern and Outcome of Obstetric Admissions into the Intensive Care Unit of a Southeast Nigerian Hospital. 2018;22(1):16-9.

18. Cdr S, Chawla S, Nakra CM, Mohan BS, Nambiar CBC, Raju C, et al. Why do obstetric patients go to the ICU? A 3-year-study. 2012;9:7-10.

19. Lapadula J, Zakalik G, Santa-maria A, Gomez RA. Characteristics, Outcomes, and Predictability of Critically III Obstetric Patients: A Multicenter Prospective Cohort Study. 2015;1887-97.

20. Okafor U V., Aniebue U. Admission pattern and outcome in critical care obstetric patients. Int J Obstet Anesth. 2004;13(3):164-6.

21. Sodhi K, Bansal V, Shrivastava A, Kumar M, Bansal N. Predictors of Mortality in Critically III Obstetric Patients in a Tertiary Care Intensive Care Unit: A Prospective 18 Months Study. J Obstet Anaesth Crit Care. 2018;8(2):73-38.

22. Pollock W, Rose L, Dennis CL. Pregnant and postpartum admissions to the intensive care unit: $A$ systematic review. Intensive Care Med. 2010;36(9):1465-74.

23. Sadler LC, Austin DM, Masson VL, McArthur CJ, McLintock C, Rhodes SP, et al. Review of contributory factors in maternity admissions to intensive care at a New Zealand tertiary hospital. Am J Obstet Gynecol [Internet]. 2013;209(6):549.e1-549.e7. Available from: http://dx.doi.org/10.1016/j.ajog.2013.07.031

24. Nates JL, Nunnally M, Kleinpell R, Blosser S, Goldner J, Birriel B, et al. ICU admission, discharge, and triage guidelines: A framework to enhance clinical operations, development of institutional policies, and further research. Vol. 44, Critical Care Medicine. 2016. 1553-1602 p.

25. Chawla S, Nakra M, Mohan S, Nambiar BC, Agarwal R, Marwaha A. Why do obstetric patients go to the ICU? A 3-year-study. Med J Armed Forces India. 2013;69(2):134-7.

26. Di Gennaro F, Marotta C, Pisani L, Veronese N, Pisani V, Lippolis V, et al. Maternal Caesarian Section Infection (MACSI) in Sierra Leone: a case control study. Epidemiol Infect. 2020;in press.

27. Okafor $U$ V., Aniebue U. Admission pattern and outcome in critical care obstetric patients. Int J Obstet Anesth. 2004;13(3):164-6.

28. Baker T, Schell CO, Lugazia E, Blixt J, Mulungu M, Castegren M, et al. Vital Signs directed therapy: Improving care in an intensive care unit in a low-income country. PLoS One [Internet]. 2015;10(12):115. Available from: http://dx.doi.org/10.1371/journal.pone.0144801 
29. Adeniran AS, Bolaji BO, Fawole AA. Predictors of maternal mortality among critically ill obstetric patients. Malawi Med J. 2015;27(March):16-9.

\section{Figures}

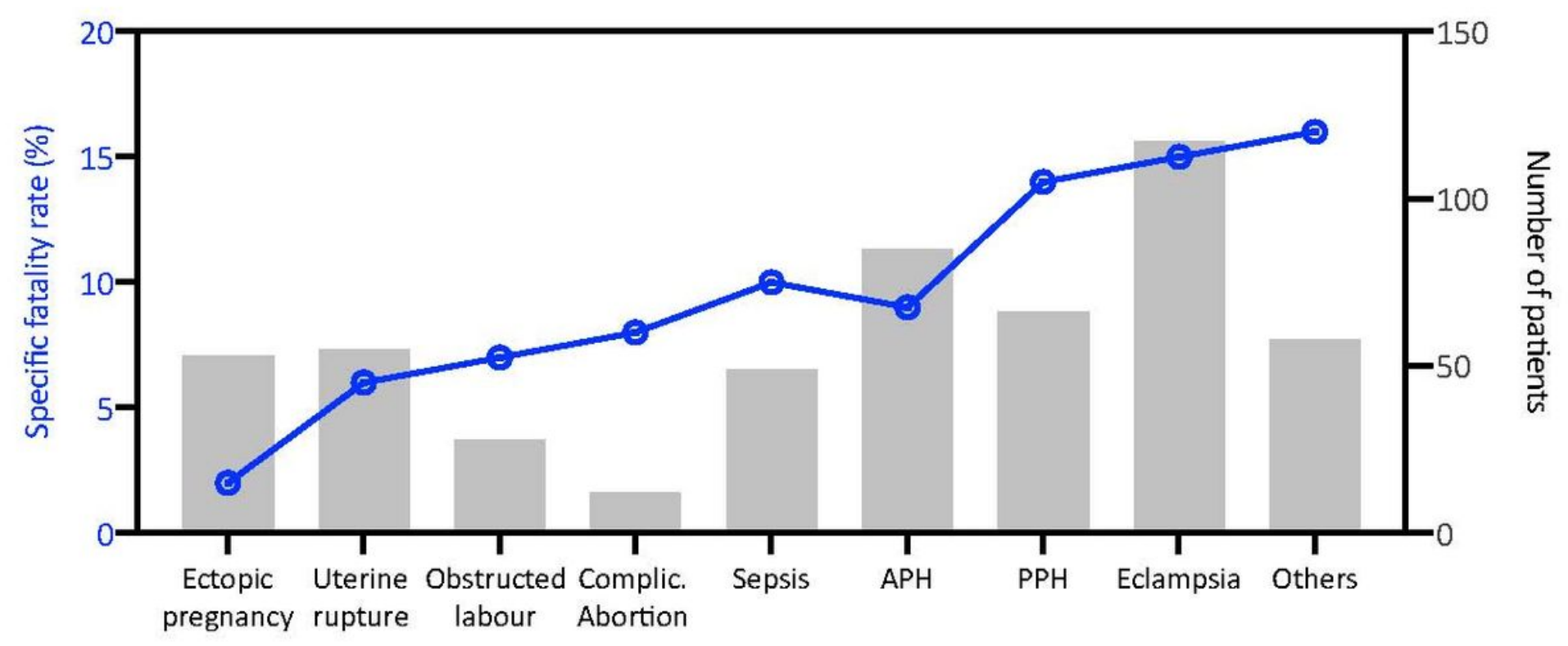

Figure 1

Number of patients and mortality rate by reason for referral to HDU. APH: ante-partum haemorrhage; PPH: postpartum haemorrhage.

\section{Supplementary Files}

This is a list of supplementary files associated with this preprint. Click to download.

- Abstract.docx

- TitlePage.docx 